\title{
Exploration on Health Management Service Mode for the Aged in Cities and Towns of Heilongjiang
}

\author{
Yexiang Yao \\ Public Health College, Qiqihar Medical University, Qiqihar Heilongjiang, 161006, China
}

Keywords: Cities and towns in Heilongjiang, the aged, Health management, Service mode

\begin{abstract}
The aging of population is severe in China, which results in the increase in health expenditure for the aged year by year. How to utilize the limited medical costs and social resources to help support old people? This issue is extensively concerned by the state, government and society. Heath departments in each place carry out health management measures for the aged. Heilongjiang Province has been devoted to the study on health management service mode for the aged. But as it starts late, relevant researches and policies are not mature enough, and many problems still exist in practice. Staring from the concept of health management, this paper, based on social security theory and health management theory, studies domestic and overseas advanced experience in health management for the aged, analyzes the current situation of public health service and health management for the aged in Heilongjiang Province, focuses on the combination of policy system, service mode, talent construction, information construction, incentive mechanism and performance appraisal of health management for the aged and provides construction suggestions on health management for the aged in Heilongjiang Province. Meanwhile, health management service mode for the aged in Heilongjiang Province is explored by considering the specific conditions of the province.
\end{abstract}

\section{Introduction}

National health system is launched in "Health China" 2013 Planning Outline. It will be more sound in 2030, and healthy life style will be popularized overall. Meanwhile, health service quality and guarantee level will improve largely. These policies indicate China pays great attention to the development of health service. As aging of population becomes increasingly severe, health and medical treatment of the aged become a major social issue. As the age grows, somatic functions gradually degrade. The probability of chronic diseases that the aged in cities and towns suffer from is $53 \% .8 .5 \%$ of the aged in cities and towns suffer from anxiety, depression and other psychological illness, which undoubtedly increases the burden to social medical treatment. It is urgently necessary for China to establish health management service mode to maintain the health right of the aged and save social medical costs.

\section{Research purpose and significance}

The survey report on aging of population issued by Heilongjiang Provincial Academy of Social Sciences in 2015 shows that, the number of the old people at the age above 60 had reached 6.089 million by the end of 2014 , accounting for $15.8 \%$ of total population in the whole province. It is predicted that the population of the aged in Heilongjiang Province will have reached 7.65 million by 2020 , accounting for $19 \%$ of total population in the whole province. As the population of the aged grows, their health becomes a major problem. As the age grows, physiological functions of the aged gradually degrade, and the morbidity increases significantly. Besides, the medical cost of the aged rises continuously. Thus, as the population of the aged continues to rise, aging problem will certainly bring about the huge pressure to the society. How to achieve healthy aging becomes an issue concerned by all countries in the world. Health management for the aged is a long-term disease prevention and health care job oriented to the aged, and it aims to offer timely, all-round and effective health service for the aged and establish the healthy and effective management mechanism through 
government intervention and top-level design. Changing unhealthy living habits of the aged through total management of health risk factors can improve health state of the aged and reduce unnecessary social waste. Thus, in the stage of severe aging problem, health management for the aged is a cause beneficial to national economy and the people's livelihood, and it has extensive development prospect.

Health management for the aged is an essential public health service of a state. Through the research for many years, certain progress and achievement have been gained in the project of health management for the aged. However, for many project undertaking units, health management for the aged is a new thing, and all kinds of problems inevitably occur in project execution process. How to well implement health management for the aged and let the aged practically enjoy material benefits is a major topic to be studied urgently. Based on social security theory and health management theory for the aged, this research aims to start from health needs of the aged in cities and towns, conduct multi-dimension and multi-level survey and analysis of health management status and needs for the aged and discover the problems in health management for the aged and the reasons. This paper analyzes health management process from the systematical perspective based on the principles of standardization, informatization and humanization and proposes constructive suggestions on health management for the aged to promote the development from pure medical service to health management. Meanwhile, health management service mode suitable for the aged in cities and towns of Heilongjiang Province is explored by combining provincial conditions.

\section{Domestic and overseas research status and development trend}

\subsection{Overseas research status and development trend}

There are many overseas research achievements on health management service for the aged. The life style, living environment and diet structure of the aged in US are the research emphases of foreign scholars, but most researches are based on scientific experiments. The researches on management are few. Foreign scholars mainly conduct theoretical research and analysis of healthy life style, health education and specific measures on health management for the aged. US entered the aging society from 1940s, and has formed highly developed health management and security system for the aged. Scholars focus on the study about life style and living habit of the aged to let the aged further abandon hazards. Laurie A analyzed the habits and adverse factors influencing living quality of the aged and advocated that the aged should develop the favorable life style and living habit. With regard to the study on health education for the aged, most foreign scholars focus on physical and psychological health of the aged. Collins-Joyce studied depression of the aged, social psychological resources and somatic functions, systematically analyzed the influence of the research content on the aged and verified the importance of health education for the aged. For health education and health promotion, MiguelA.perez also studied the relationship between health education and health promotion. Foreign scholars have conducted many researches on the measures to improve health management for the aged. British scholar Caroline considered that, it is required to clarify capital sources and establish primary health care organization on the basis of improving health and social service structure. Some scholars also thought, health management for the aged should be included in the scope of social insurance so as to improve health level, reduce medical cost, intervene in advance by medical insurance and change passiveness to activeness. Meanwhile, health inquiry and physical examination services may be offered for the aged to gain first-hand health information data.

\subsection{Domestic research and development trend}

China entered the aging society from the end of 1990s, so the relevant research started late. Supervision and management aim to examine, analyze and evaluate individual physical condition, offer targeted health consultation and guidance according to health assessment result, intervene in people's life style and living habit scientifically and reduce hazards triggering diseases. health management strategies for the aged include life style and living habit management, chronic disease management, health file establishment, physical examination, informatization management and 
medical service. To construct health management service mode for the aged with Chinese characteristics is our inevitable choice. In recent years, under the government's policy promotion, health management work for the aged has been indeed carried out effectively in some regions, but there is lack of laws, regulations and continuity. The new healthcare reform scheme has clearly proposed to drive legislative work for basic medical care, and specifies the responsibilities, rights and obligations of the government and society. The researches of $\mathrm{Wu}$ Xiuyun et al. on the factors influencing health service intention of urban residents in Beijing indicate that, the main factors influencing the intention of accepting community health service include age, gender, educational background, occupation, medial cost undertaking mode and illness. At present, domestic researches on health management for the aged mainly focus on health service in some first-tier cities with developed economy, such as Shanghai, Tianjin and Guangdong, or concentrate on some rural areas with underdeveloped economy. But, these researches mostly involve theoretical contents and the government's administrative intervention, while the contents about government investment and incentive mechanism are insufficient, which may result in insufficient investment and effect proportion.

Based on the views of domestic and overseas scholars, there is short of policy system study on health management for the aged, and the researches on service mode are few. Meanwhile, there is lack of the research on combination of professional talent construction, information construction, incentive mechanism and performance appraisal. This paper pays attention to and studies the above five aspects.

\section{Health management for the aged in cities and towns of Heilongjiang Province and current situation of service development}

Health management for the aged in cities and towns of Heilongjiang Province and service status

The domestic definition of health management for the aged is vague. For foreign research experience, health management for the aged is to establish health management field by social medical organization after assessment of health risks of the aged and to intervene their living habit in a targeted and scientific way according to their health assessment report so as to control their morbidity, reduce hazards for illness and construct an all-round supervision and management mode.

The special research group is built for health management service mode for the aged in cities and towns of Heilongjiang Province. Document research, investigation, interview and statistical analysis are combined to explore development status of health management service for the aged in cities and towns of Heilongjiang Province. The exploration path is shown in fig.1.

It is found that, the policy and planning of Heilongjiang Province for health management service for the aged in cities and towns are still in the initial stage. Health management institution setting is not sound. There is lack of corresponding laws and regulations. The establishment of health management files for the aged is not sound. There is no awareness of establishing electronic information file. Although the health department of Heilongjiang Province enhances the attention to health management for the aged and construction of health management service mode, and is also devoting itself to offering basic health management service for the aged with the help of community healthcare center, the occurrence probability of chronic diseases of the aged such as hypertension and diabetes also gradually increases due to social and individual reasons. For such common chronic diseases, the effective health management mode has not been established so far. Only such methods as enhancing health knowledge popularization, prevention and treatment can be taken to reduce the probability of illness occurrence. Health management development and governments at all levels in Heilongjiang Province receive the slight effect on health management service measures. Due to the limits of various objective and human factors, health management service for the aged in cities and towns cannot be implemented well, and the health need of the aged cannot be met. Besides, medical health cost cannot be saved. 


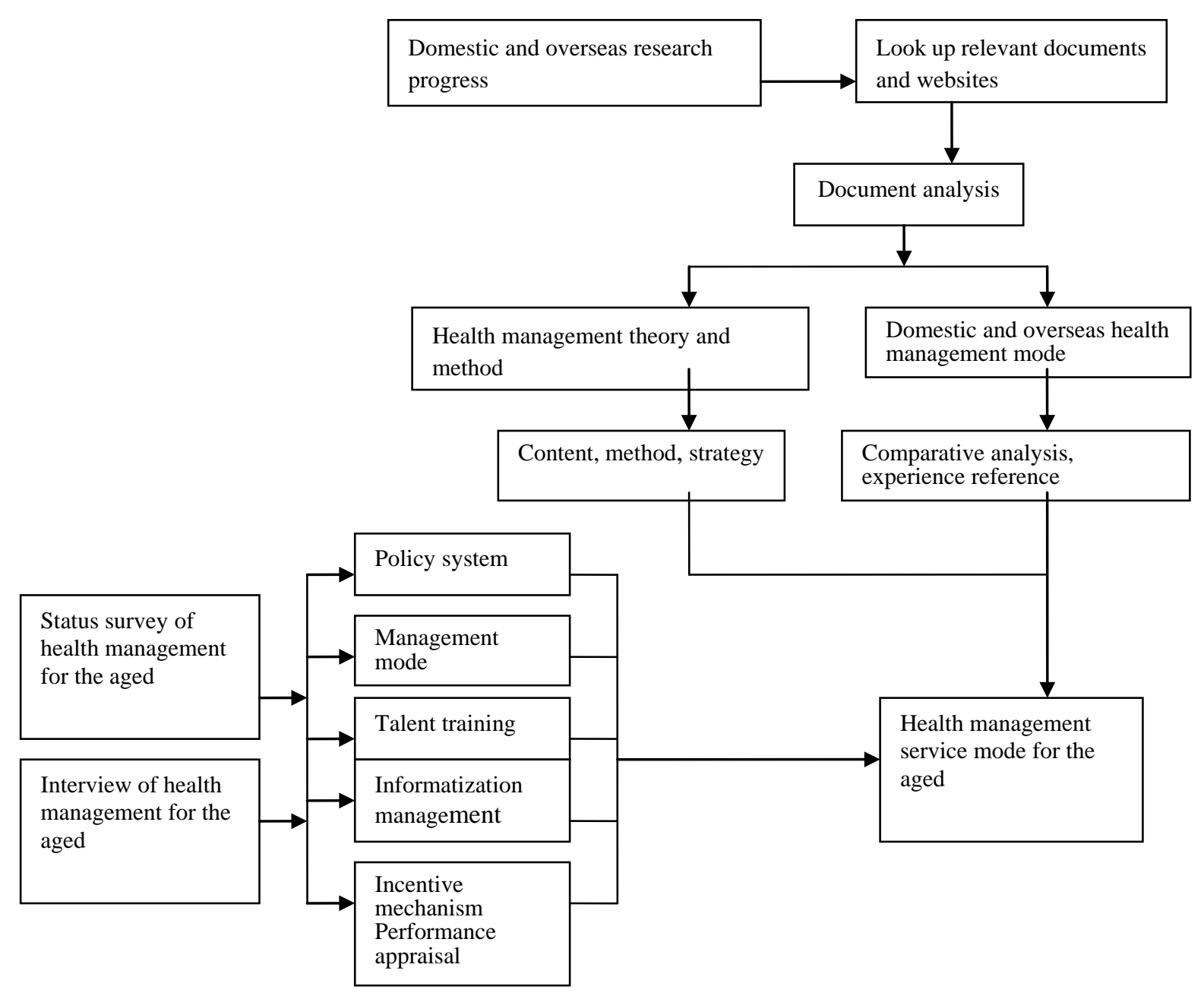

Fig.1 The exploration path

All types of health management modes emerge in endlessly, but sustainable health management development mode cannot form, and the favorable health management service cycle cannot form. In the final analysis, there is no sound health management policy system and lack of professional talents, and resources cannot be shared. Thus, the research group put forward the suggestions on solving these problems through long-term practical study.

\section{Constructional path for health management service mode for the aged in cities and towns of Heilongjiang}

\subsection{To construct the service mode for the aged with Chinese characteristics}

Health management service for the aged has public welfare property and profitability, and it needs the participation and support from the government and society. Thus, it is required to actively construct health management mode for the aged in which government and society participate. The government shall give play to its functions of policy making and maintenance. Private community and private sector shall be responsible for executing the policy. Such management mode can help the government relieve financial burden, attract more social forces, enhance civic awareness and sense of social identity and improve resource utilization efficiency and construction.

\subsection{To establish and improve management system and carry out standardized management}

Policy implementation needs legal support, or else buck-passing phenomenon will occur. To establish and improve health management system and carry out standardized management, firstly, the rights and obligations of government and social organization should be specified. In the implementation process, the government should neither let go completely nor exceed its duties. The 
responsibility boundary of government and society should be clear. Secondly, the government chooses the social organization, and the social organization should completely depend on the government's funds. Finally, the sound health management service supervision mechanism and complaints mechanism should be constructed to make the aged can directly supervise health management service.

\subsection{To establish incentive mechanism and performance appraisal method}

The society should enhance talent training. Besides, the health department and health management service department should construct sound incentive mechanism and performance appraisal method. Relevant departments must clearly divide the duties of each worker, train workers regularly, bring the training performance into the performance appraisal and award the employees outstanding performance and punish those with poor performance.

\section{Conclusions}

Health management service for the aged is the health care defilement direction. To improve health management service system and mechanism and innovate management means is the foundation for constructing an orderly health management service market. Scientific planning health care mode of the aged, saving medical resource and reducing national medical burden for the aged have great significance for social economy and social ethics development. This paper takes the aged in Heilongjiang Province as the respondents, in the hope of offering theoretical foundation for constructing management service mode for the aged in China.

\section{Acknowledgements}

This research was financially supported by the Health Management Service Mode for the Aged in Cities and Towns of Heilongjiang (2016-KYYWF-0903), It is the fundamental research project of Heilongjiang Education Department of Heilongjiang Province.

\section{References}

[1] Deng Jing, Jiang Shizhen, Study on China's Health Needs under the Background of Population Aging, Hospital Management Forum, 2013,03.

[2] Xie Wenxiu, Shi Min, Essential Public Health Service and Health Management, Journal of Frontiers of Medicine, 2015, 08.

[3] Shao Gang, Xu Aijun, Xiao Yue, Zhao Hun, Shan Tingting, Research progress on development of health industry in foreign countries, China Medical Herald, 2015, 17.

[4] Zhang Yue, Wu Jianguo, Lu Jianhua et al., The Inspiration on the Disease Management in China from the Experience in Health Management Abroad, Jiangsu Healthcare Administration, 2011, 22.

[5] Li Jiang, Tao Shao, Li Ming et al., The Current Situation and Development of Health Management in China, Engineering Sciences, 2017, 02. 